\title{
IMAGENS DE SATÉLITES NO AUXILIO DA EDUCAÇÃO AMBIENTAL: O ESTUDO DA SUB-BACIA DO RIO VACACAÍ-MIRIM COM ALUNOS DA ESCOLA ESTADUAL PROFESSORA MARGARIDA LOPES.
}

\author{
Evanise Dos Santos Costa, Damaris Kirch Pinheiro
}

\begin{abstract}
RESUMO
A utilização dos recursos naturais de maneira intensa pelo homem causou a degradação do meio e, conseqüentemente, a preocupação da sociedade como um todo com os problemas ambientais. Surge, assim, a urgente necessidade de se ter um olhar mais observador e crítico nas questões do meio. A Educação Ambiental serve de auxílio nesta mudança de hábito e as novas tecnologias ganham cada dia mais espaço nos lares, empresas e escolas. Neste sentido, buscando utilizar estas tecnologias como um recurso didático rico em informações, este artigo tem o objetivo principal de inserir imagens de satélites, através da ferramenta atual Google Earth, na Escola para a compreensão de problemas ambientais da sub-bacia do Vacacaí-Mirim. Esta pesquisa foi baseada no método indutivo, ou seja, uma pesquisa de natureza aplicada. Para tanto, foi aplicado um projeto na Escola Estadual Professora Margarida Lopes, em que foi desenvolvido um questionário com os alunos para uma avaliação prévia do que seria abordado na pesquisa. Os resultados deste questionário foram comparados aos resultados de um segundo questionário aplicado após as atividades realizadas com imagens de satélites.

Através das atividades realizadas foram obtidos alguns resultados que estão expostos a seguir neste artigo.
\end{abstract}

Palavras-chave: Educação Ambiental, Imagens de satélites, Vacacaí-Mirim.

\section{ABSTRACT}

The use of natural resources by man has caused intense degradation of the environment and therefore society's concern about environmental problems, so changing habits is something necessary. In this context, environmental education helps to make these changes possible. More than ever, new technologies are getting space in our homes, offices, and schools. In this sense, seeking to use these technologies as a teaching resource, this paper had the main goal of getting students into contact with Google Earth satellite's images in order to help them to understand environmental problems related to Vacacaí-mirim hydrographic sub-basin. Environmental education as education in a general sense needs to dynamic, because of that, thinking about innovative teaching methodologies as well as innovative educational materials are essential. This research was based on the inductive method with an applied nature. The project was developed in the state school Professora Margarida Lopes (in Santa Maria city, Brazil), where a questionnaire was applied to a group of teenagers and adults students in order to have a preliminary assessment what would be covered by the research. Later on, an informal conversation about environmental issues with emphasis on Vacacaí-mirim sub-basin was conducted by the researcher. After that, the students were taken to the laboratory where a work on how to use satellite images was carried out. The results of this laboratory work were evaluated by a final questionnaire. Some of these results are presented and discussed in this paper. 
Keywords: Environmental Education, satellite images, Vacacaí-mirim sub-basin.

\section{INTRODUÇÃO}

O homem, em seu processo evolutivo de consolidação enquanto sociedade, utilizou os recursos naturais de diferentes formas, não havendo uma preocupação com as consequências da expropriação dos bens naturais, que se tornou mais evidente após a Revolução Industrial.

A partir da década de 60 a preocupação com os problemas gerados pela exploração inadequada do meio-ambiente passa a ser discutida e se inicia a busca por soluções para problemas referentes ao meio-ambiente, tanto natural quanto social. Assim, a Educação Ambiental passa a ganhar espaço no âmbito formal e informal.

O trabalho com Educação Ambiental tende a desenvolver nos alunos não só a consciência ambiental, mas também a social e a cultural, preparando o aluno para entender esta grande teia que é a relação homem $X$ meio.

As novas tecnologias vêm auxiliar no trabalho em sala de aula, podendo ser utilizadas como ferramentas de ensino em muitos casos. Este trabalho possui como objetivo principal inserir as imagens de satélites, através do Google Earth na Escola, para a compreensão de problemas ambientais da sub-bacia do Vacacaí-Mirim.

Neste sentido espera-se que as imagens de satélites venham a auxiliar os alunos na compreensão dos problemas ambientais na sub-bacia Vacacaí-Mirim, sendo esta a hipótese do trabalho.

As novas tecnologias apresentam um leque de informações disponíveis, muitas vezes de maneira gratuita que, se utilizadas corretamente, podem ser de grande valia para o ensino. Desta maneira, ao utilizar imagens de satélites, o professor proporciona ao aluno, além do contato com novas tecnologias, uma maneira diferenciada de trabalhar com conteúdos e trocar informações, podendo colaborar, impreterivelmente, na formação do aluno.

\subsection{Objetivos}

\subsubsection{Objetivo Geral}

Esta pesquisa teve como objetivo geral inserir as imagens de satélites através do programa atual Google Earth na Escola para a compreensão de problemas ambientais da sub-bacia do Vacacaí-Mirim.

\subsubsection{Objetivos Específicos}

- Usar imagens de satélites como ferramenta de ensino através do programa computacional Google Earth em sala de aula;

- Identificar problemas ambientais ocorrentes na sub-bacia do Vacacaí-Mirin através de imagens de satélites;

- Avaliar a contribuição da ferramenta Google Earth para o ensino de Educação Ambiental através de tal experiência. 


\section{REVISÃO TEÓRICA}

\subsection{A Educação Ambiental}

Na década de 60 surgem, de maneira mais intensa, os movimentos em favor do meio ambiente; é neste momento que os problemas ambientais tornam-se ainda mais evidentes, principalmente pela poluição gerada pelo crescimento econômico de países como Inglaterra, Estados Unidos e França. Em decorrência disso, começam a surgir denúncias das agressões que o meio vinha sofrendo, bem como alertas às consequências da exploração inadequada dos recursos naturais, conforme Dias (2001, p.78),

\footnotetext{
"Sem nenhuma preocupação com as consequências de suas atividades a jornalista americana Rachel Carson lançava o seu livro Primavera Silenciosa (formato bolso, 1962, 44 edições), que viria a se tornar em clássico na história do movimento ambientalista mundial, desencadeando uma grande inquietação internacional e suscitando discussões nos diversos foros".
}

Diante desse panorama global de apreensão em relação à degradação dos recursos naturais, há o claro objetivo de debater os problemas ambientais através de encontros e congressos, bem como criar ajustes na utilização dos bens naturais e promover atitudes conscientes dos problemas que a intensa utilização destes bens estava causando no planeta.

\subsection{Estudos dos Impactos Ambientais através da Educação Ambiental}

Ao longo do tempo percebe-se com clareza a deterioração da qualidade do ambiente não só natural, mas também humana, e cada vez evidencia-se mais a necessidade de mudanças de hábitos, aliada à conscientização e sensibilização de atos relacionados ao meio ambiente. Estes atos refletem diretamente na qualidade, preservação e recuperação do meio, intervindo também na qualidade de vida dos seres humanos e, conseqüentemente, dos demais seres vivos.

A perda da qualidade ambiental exige novas formas de pensar, atuar e relacionar-se com o meio ambiente, neste sentido a Educação Ambiental nasce voltando suas atenções para a relação do homem com o meio.

A Educação Ambiental oportuniza a sensibilização do ser humano com as atitudes e atividades que interferem e transformam os espaços naturais e socioculturais, proporcionando a mudança de atitude do ser humano e novas formas relacionais com o meio ambiente. Segundo Reigota,

"um lugar determinado e/ou percebido onde estão em relações dinâmicas e em constante interação os aspectos naturais e sociais. Essas relações acarretam processos de criação cultural e tecnológica e processos históricos e políticos de transformação da natureza e da sociedade". (REIGOTA, 1994, p. 21)

Através da Educação Ambiental é possível suscitar a consciência ambiental e social, melhorar o entendimento da enorme teia que é o meio ambiente. 
REMOANFSM

\title{
2.3. Imagens de Satélites
}

Os vários satélites que estão em órbita representam um instrumento gerador de vasta gama de informações aos seres humanos sendo utilizados em empresas, órgãos públicos, ambientes escolares e uso doméstico.

Os satélites artificiais surgem para auxiliar e acrescentar ainda mais as técnicas de mapeamento. Romeiro (apud RASH, 2004, p 34) escreve que,

"iniciando em 1972 com o lançamento do satélite Landsat e reforçado com o lançamento, em 1986, do satélite Spot, que apresentada melhorias de resolução espacial temporal em relação ao primeiro, o sensoriamento remoto por satélites assumiu grande importância nos trabalhos de análise e monitoramento ambiental em âmbito local, regional e global".

Hoje, as imagens de satélites são um recurso bastante acessível e podem ser utilizadas em sala de aula, mas embora seja encontrado gratuitamente em sites, ainda são pouco empregados por professores e alunos. Para Florenzano (2002, p. 93),

\begin{abstract}
"embora cada vez mais freqüentes nos meios de comunicação visual, e, livros, atlas e em eventos relacionados à educação e ao meio ambiente, e apesar do seu grande potencial como recurso didático, as imagens de satélites são ainda pouco exploradas para essa finalidade, tanto no ensino fundamental, médio, como no ensino superior".
\end{abstract}

Os dados obtidos através do sensoriamento remoto podem ser utilizados na educação em diversas áreas do conhecimento; para tanto o professor deve ser mediador das atividades realizadas em sala de aula e proporcionar momento de aprendizado.

\section{METODOLOGIA}

O projeto de pesquisa que deu origem a este trabalho foi aplicado na Escola Estadual Professora Margarida Lopes, localizada no bairro Camobi, no município de Santa Maria/RS. A escola foi escolhida por localizar-se em um bairro banhado pelo rio principal da sub-bacia VacacaíMirim. A sub-bacia do rio Vacacaí-Mirim está localizada na região central do estado do Rio Grande do Sul, pertencendo à bacia do rio Vacacaí. O rio principal, o Vacacaí-Mirim, tem sua nascente no alto da Serra Geral, no município de Itaara/RS, seguindo em direção à depressão central e tendo sua foz no rio Jacuí, no município de Restinga Sêca/RS.

Esta bacia abrange seis municípios do Rio Grande do Sul, são eles: Itaara, Júlio de Castilhos, Santa Maria, Silveira Martins, Restinga Sêca e São João do Polêsine.

A metodologia utilizada neste trabalho de pesquisa baseou-se no método indutivo, conforme Marconi e Lakatos (2003, p. 86), "indução é um processo mental por intermédio do qual, partindo de dados particulares, suficientemente constatados, infere-se uma verdade geral ou universal, não contidas nas partes examinadas."

$1^{\circ}$. Aplicou-se um questionário para uma avaliação prévia sobre o assunto a ser abordado em sala de aula.

$2^{\circ}$. Fez-se uma explanação sobre a importância da água, bacias hidrográficas e impactos ambientais, e foi entregue material impresso sobre o tema abordado. 
REMOANFSM

$3^{\circ}$. Apresentou-se aos alunos o programa computacional Google Earth no laboratório de informática com a finalidade de trabalhar com as imagens de satélites de temas livres.

$4^{\circ}$. Foram utilizadas as imagens de satélites para diagnóstico de problemas ambientais na sub-bacia do Vacacaí-Mirim.

$5^{\circ}$. Aplicou-se o segundo questionário com o objetivo de avaliar a aprendizagem dos alunos e a experiência que estes tiveram.

$6^{\circ}$. Tabularam-se os dados.

$7^{\circ}$. Analisaram-se os resultados.

\section{DISCUSSÃO DOS RESULTADOS}

\subsection{Dados sobre acesso da internet e Google Earth}

Com relação ao acesso a internet, foi obtido o seguinte resultado: $80 \%$ dos alunos possuem acesso a internet enquanto que $20 \%$ não.

O trabalho com imagens de satélites foi realizado no laboratório de informática da escola, onde todos teriam acesso a computadores. Nesse sentido, é necessário pensar que, nos dias atuais, ter acesso a tecnologias modernas é essencial.

Em virtude disso, as escolas devem proporcionar práticas que possibilitem a relação do aluno com novas tecnologias. Se trata de um momento de aprendizagem, tanto de conteúdos quanto de trabalho com novas tecnologias. Moran et al. (2003, p. 103) dizem que

\footnotetext{
"os principios da técnologia da informação auxiliam o entendimento de que a informática pode ser instrumento afinado perfeitamente com os projetos de aprendizagem e com as práticas pedagógicas, desde que haja um gerenciamento adequado dos recursos informatizados".
}

Dos $80 \%$ dos alunos que responderam ter acesso a internet, $94 \%$ deles acessa a internet em casa, enquanto que $6 \%$ acessam em locais comerciais. Dos alunos participantes da pesquisa, $60 \%$ conheciam o software Google Earth e $40 \%$ não. Dos cerca de $60 \%$ que conheciam o Google Earth, 50\% já haviam utilizado o software com alguma finalidade.

\subsection{Dados sobre temas abordados com os alunos em sala de aula}

Dos 20 alunos que responderam ao questionário, 45\% disseram saber o que é uma bacia hidrográfica e $55 \%$ disseram não saber.

Questionados sobre o que era impacto ambiental e sua conceituação, 55\% dos alunos responderam saber e foram capazes de conceituá-lo e $45 \%$ não sabiam e não conseguiram conceituar.

$\mathrm{Na}$ segunda etapa, foram trabalhados temas relacionados a bacias hidrográficas e os principais impactos ambientais que estas sofrem. Nesse sentido foi entregue material impresso que guiou o diálogo com a turma. Em virtude de a escola estar localizada próxima ao rio principal da sub-bacia Vacacaí-Mirim, os próprios alunos utilizaram o rio Vacacaí-Mirim como exemplo de impactos ambientais durante o diálogo. Conforme ia avançando o debate, passaram a dar seus depoimentos baseados na relação que possuíam com o rio. Neste momento, a pesquisadora 
questionou o que era uma bacia hidrográfica, rio principal, afluentes e divisores d'água, mas nenhum aluno da turma soube explicar o que era, diferente do apresentado nos gráficos 7 e 8 , nos quais, respectivamente, $45 \%$ respondeu saber o que é uma bacia hidrográfica e $60 \%$ respondeu saber o que é um rio afluente.

A pesquisadora aproveitou os exemplos dos alunos para tratar de questões previamente estabelecidas, quais sejam bacias hidrográficas e impactos ambientais, associando com temas mais amplos sobre meio ambiente. Este momento caracterizou-se pela troca de experiência entre pesquisadora e alunos. Para Guimarães (1995, p.36),

"na educação ambiental as diversidades devem ser trabalhadas pelo educador, de modo que sensibilize o educando de acordo com sua realidade local, ou seja, trabalhar a vivencia imediata para chegar a uma vivencia plena".

$\mathrm{Na}$ terceira etapa, os alunos foram encaminhados ao laboratório de informática da escola. Nesse momento, foi apresentado o software Google Earth e eles foram instruídos sobre como utilizá-lo. Foram apresentados os principais aplicativos do programa. Deixados livres para conhecer o programa, eles puderam viajar pelo planeta, localizar cidades, a cidade onde nasceram ou onde moram, ir até pontos de sua preferência.

Neste momento, os alunos foram, virtualmente, até suas casas através das imagens de satélites, encontraram a escola onde estudam, foram até o local onde trabalham. Em momentos de dificuldade, os alunos recorreram à pesquisadora, buscando orientação. Pode-se considerar esta etapa como um período de adaptação ao uso do Google Earth.

No quarto momento da pesquisa foi pedido para que os alunos visualizassem no Google Earth a sub-bacia do rio Vacacaí-Mirim, já lançada no programa, onde primeiro observaram a área total da bacia hidrográfica e sua ocupação. Após, começaram a fazer uma viagem através de imagens de satélites, desde a nascente do rio principal no município de Itaara/RS, (ver figura 10), até sua foz no rio Jacuí, município de Restinga Sêca/RS, (ver figura 11). Conforme os alunos avançavam na viagem virtual, passaram a pontuar problemas ambientais referentes à sub-bacia, compartilhando com a pesquisadora e os demais alunos (Figura 9) Reigota (1994, p.14) escreve,

\footnotetext{
“A Educação Ambiental apresenta-se como uma dimensão do processo educativo voltada para a participação de seus atores, educandos e educadores, na construção de um novo paradigma que contemple as aspirações populares de melhor qualidade de vida socioeconômica e um mundo ambientalmente sadio".
}

Os alunos chamaram a atenção para impactos como construções de moradias e indústrias às margens do rio principal, o seu desmoronamento e as plantações próximas aos rios que compõe a sub-bacia. Mais uma vez trouxeram para a sala de aula as experiências e observações acerca do bairro onde residem. Uma aluna associou a falta de saneamento básico no bairro à contaminação do lençol freático e, conseqüentemente, dos cursos d'água. Outra aluna explanou sobre a contaminação por dejetos domésticos dos afluentes do rio Vacacaí-Mirim, no bairro Camobi e, conseqüentemente, contaminando o rio principal.

Florenzano (2002, p.22) escreve 


\begin{abstract}
"Dessa forma, explorar com recursos de sensoriamento remoto, inicialmente, regiões conhecidas do aluno favorece a descrição dos elementos presentes na paisagem, familiarizando-o com esta forma de representação do espaço. Deixar que o aluno observe uma imagem durante o tempo que for necessário para localizar sozinho seus principais elementos, sobretudo os constitutivos da sua cidade, permite que este "se encontre" nesta paisagem".
\end{abstract}

Embora os alunos desconheçam termos técnicos, como mata ciliar e assoreamento, foram capazes de explicar algumas das mudanças ocorridas na sub-bacia. Inclusive relataram que existe uma empresa no bairro que desviou o curso natural do rio, utiliza de suas águas e despeja resíduos sólidos nas margens e leito do rio. Lembraram que próximo à escola onde passa o rio principal da sub-bacia fica um dos pontos mais visíveis da falta de mata ciliar e conseguiram associar as causas e conseqüências da ausência dela.

Para Reigota (1994, p. 26),

na educação ambiental escolar deve-se enfatizar o estudo do meio ambiente onde vive o aluno, procurando levantar os principais problemas da comunidade, as contribuições da ciência, os conhecimentos necessários e as possibilidades concretas para as soluções deles".

Através dos exemplos dos alunos, a pesquisadora guiava a discussão sobre a importância da bacia hidrográfica para a região, bem como a importância de utilizar as áreas de bacias com consciência e como os problemas que ali ocorrem poderiam ser resolvidos. A turma, na íntegra, se envolveu com as atividades propostas e colaborou com suas visões e experiências, sendo que a diferença de idade entre os alunos proporcionou a troca de informações sobre o rio em visões de diferentes épocas.

A quinta etapa abrangeu a aplicação do segundo questionário, buscando avaliar a aprendizagem dos alunos e a experiência que tiveram.

Dos alunos que participaram da pesquisa, $100 \%$ disseram gostar das atividades desenvolvidas com o software Google Earth.

Tabela 1 - Resposta dos alunos quando questionados se gostaram ou não das atividades com a ferramenta atual Google Earth.

\begin{tabular}{c|c}
\hline Resposta & \% de alunos \\
\hline sim & 100 \\
\hline não & 0 \\
\hline
\end{tabular}

Apenas $6 \%$ dos alunos disseram ter dificuldades em trabalhar com o Google Earth.

Tabela 2 - Resposta dos alunos quando questionados se Google Earth auxiliava na compreensão sobre e entendimento do que é uma bacia hidrográfica.

\begin{tabular}{l|l}
\hline Resposta & \% de alunos \\
\hline sim & 100 \\
\hline não & 0 \\
\hline
\end{tabular}


Quanto à compreensão dos problemas ambientais, 94\% consideram que o Google Earth ajudou no aprendizado e $6 \%$ consideram que não. Questionados sobre os componentes da subbacia do rio Vacacaí-Mirim, 65\% responderam ser o desmatamento e agricultura intensa até as margens dos rios, $29 \%$ o rio principal, seus afluentes e divisores de água d'água e $6 \%$ a fauna e flora local. Levando em consideração que a resposta correta para tal questão é rio principal, seus afluentes e divisores d'água, $71 \%$ dos alunos escolheram a alternativa incorreta.

Através de observação de imagens de satélites, $71 \%$ dos alunos concluíram que a maior porção da área da sub-bacia encontra-se em meio rural e $29 \%$ que se encontra em meio urbano. Nesse sentido, $71 \%$ dos alunos chegaram à conclusão correta.

Tabela 2 - Percentual de alunos que disseram saber o que é impacto ambiental e deram alguma definição para impacto ambiental.

\begin{tabular}{l|l}
\hline Resposta & \% de alunos \\
\hline sim & 100 \\
\hline não & 0 \\
\hline
\end{tabular}

\section{CONCLUSÃO}

Através do trabalho realizado com a turma T8 do EJA (Educação de Jovens e Adultos) na Escola Estadual Margarida Lopes, com a utilização de imagens de satélites através do software Google Earth, verifica-se que, em geral, os alunos se mostraram interessados com esta ferramenta de ensino. A grande maioria não apresentou dificuldades em manusear o programa, bem como em diagnosticar e localizar problemas ambientais na sub-bacia do rio Vacacaí-Mirim. Neste sentido, foi alcançado o principal objetivo desta pesquisa, o de inserir as imagens de satélites através do Google Earth na Escola para a compreensão de problemas ambientais da sub-bacia do Vacacaí-Mirim.

Muitos alunos relataram ser a primeira vez a terem utilizado imagens de satélites e o programa Google Earth para fins educacionais, mesmo assim foi possível trabalhar os temas propostos com boa participação dos alunos, o que gerou momentos de grande troca de conhecimento e pode ser percebido o envolvimento de toda a turma nas atividades.

Através dos questionários aplicados antes das atividades e ao final destas, pode-se concluir que os alunos tiveram dificuldades nos assuntos relacionados à compreensão do que é uma bacia hidrográfica e quais são os componentes que a formam. Esta dificuldade pode ser percebida desde a primeira aula, sendo que após o desenvolvimento das atividades os alunos ainda mostraram dificuldade em perceber o que era uma bacia hidrográfica. Através do segundo questionário, pode-se notar que os alunos descreveram como problemas ambientais mais graves na sub-bacia os problemas que ocorrem em seu bairro, os quais eles entendem serem os mais graves, talvez por que são os que estão mais próximos a eles.

Durante as conversas realizadas em sala de aula, pode-se perceber que os alunos conseguiram relacionar várias informações sobre meio ambiente e impactos ambientais.

Foi possível também observar que a compreensão sobre o que são impactos ambientais e comparando os resultados do primeiro questionário com o segundo, houve um crescimento significativo entre os alunos que conseguiram conceituar o que é um impacto ambiental, mostrando assim que conseguiram assimilar as discussões geradas em sala de aula. 
REMOANFSM

Assim, pode-se afirmar que as imagens de satélites ainda são pouco utilizadas nas escolas, mas que, no geral, são válidas como uma ferramenta de ensino, por apresentar-se como um recurso diferenciado que atrai a atenção dos alunos, bem como pode ser utilizada para detectar problemas ambientais, além de suas ferramentas proporcionarem grande gama de informações, principalmente relacionadas ao meio ambiente e estudos ambientais, assim a pesquisa confirmou a hipótese como esperado.

\section{REFERÊNCIAS}

DIAS, Genebaldo Freire, Educação Ambiental princípios e práticas. $7^{\circ}$ Ed. Gaia. São Paulo,2001.

FLORENZANO, Teresa Gallotti. Imagens ambientais para estudos ambientais. São Paulo: Oficina dos textos, 2002.

GUIMARÃES, Mauro. A dimensão Ambiental na Educação. Papirus, Campinas-SP, 1995.

MORAN, José Manuel et AL. Novas tecnologias e mediações pedagógicas. $7^{\circ}$ Ed. São Paulo. Papirus, 2003.

REIGOTA, Marcos. O que é Educação Ambiental. Ed. Brasiliense, São Paulo. 1994.

ROMEIRO, Ademar R. (Org.). Avaliação e contabilização de impactos ambientais.Campinas: Editora Unicamp, São Paulo: Imprensa Oficial do Estado de São Paulo, 2004. 